\title{
Navigating TRAP Laws, Protesters, and Police Presence at a Midwestern Abortion Clinic in the United States: A Case Study
}

\author{
Shara Crookston ${ }^{1 *}$
}

Published: September 8, 2020

\begin{abstract}
Patient-level outcomes are frequently the focus of research on restrictive abortion laws, and qualitative literature examining the experiences of volunteers and non-physicians is sparse. To better understand how TRAP (Targeted Regulation of Abortion Provider) laws and abortion restrictions affect abortion clinic operations in the United States, I conducted a case study of 11 non-physician staff and volunteers at an abortion clinic in a low-income, Midwestern city. Findings include participants negotiating troublesome and costly TRAP laws, specifically the process of obtaining a transfer agreement with a local hospital in order to stay open. Study participants felt safe at the clinic due to their relationship with local police. Lastly, participants commented on a recent increase in protester presence, but acknowledged that other clinics experience even worse harassment. I conclude that non-physician experiences should be included when we are examining the impact of TRAP laws and abortion restrictions if we are to provide a more nuanced understanding of the complexities of abortion work. These interviews provide qualitative data on the experiential evidence of the impact of TRAP laws and abortion restrictions which are the consequence of various Supreme Court decisions over the past several decades.
\end{abstract}

Keywords: abortion, abortion clinic, abortion restrictions, TRAP laws

\section{INTRODUCTION}

Berer (2017: 13) notes that from a global perspective, the 'plethora of convoluted laws and restrictions surrounding abortion do not make any legal or public sense' and serve to prevent making abortion universally affordable, accessible, and safe. This trend can be seen in the United States where, according to Andaya and Mishtal (2016: 40), women's rights to legal abortion are 'now facing their greatest social and legislative challenges since its 1973 legislation' following the landmark Roe vs. Wade case. Under the Trump administration, 25 new bans have been signed into law, primarily in the Southern and Midwestern United States in 2019 alone (Nash, Mohammed, Cappello and Naide, 2019), which has far-reaching implications for women's health care. In the United States, abortion is commonly treated differently from other medical procedures and providers must routinely comply with legal obligations that go beyond standards of professional ethics and practice (Sedgh et al., 2012), making safe, affordable and accessible abortion difficult to obtain. Individual states may pass laws that restrict access to abortion by insisting on mandatory waiting times as well as biased counselling and limited public funding. While first trimester induced abortion is not uncommon (nearly 1 in 4 women) (Jones and Jerman, 2017), access to this legal form of health care is heavily controlled in many states. A number of studies on restrictive abortion laws focus on patient access (Kimport et al., 2012), while others consider abortion stigma (Cockrill and Nack, 2013), or broader implications for public health such as maternal mortality (Britton et al., 2017).

Provider and non-provider experiences have received less attention (see Britton et al., 2017; Medoff, 2009), making this an important area for critical inquiry and the focus of this case study. The insufficient attention being paid to non-physician clinical staff and volunteers means that this population is rendered invisible and the impact of their experiences on dedicated patient care and the stability and preservation of abortion access is neglected. Mercier et al., (2017: 77) have argued that a framework that is focused on the impact of abortion laws for patients may 'inadvertently overlook the key, and often invisible, work undertaken by abortion providers to minimize the burden on women and preserve abortion access'. This study addresses this overlooked population. 
Abortion stigma must be addressed in any study on non-physician staff and volunteer experiences at clinics as part of their psychological burden. Restrictive abortion laws may contribute to and reinforce abortion stigma, furthering negative public perception about abortion providers (Britton et al., 2017; Harris et al., 2011; Kumar et al., 2009) and the devalued so-called dirty work that accompanies abortion (Debbink et al., 2016). Martin et al. (2014: 641) established that stigma surrounding abortion work was prevalent in most providers' lives with 66\% of study participants citing difficulties in relation to disclosure and $89 \%$ feeling unappreciated by society. Providers reported that few opportunities for connection to others with similar experiences left them feeling disconnected and vulnerable (Harris et al., 2011; Harris, et al., 2013). Simultaneously, $92 \%$ of participants felt that they made a positive contribution to society and 98\% took pride in their work (Martin et al., 2014), showcasing the complexity of abortion work for providers. By investigating the experiences of those who work closely with patients seeking abortion care, a clear understanding of how TRAP laws and other state sanctioned restrictions affect clinic staff and volunteers emerges. It is essential to examine the critical and often invisible care labour undertaken by nonphysician staff as clinics continue to close, patient volumes increase and abortion access becomes more restricted. In sum, Britton et al. (2017: 233) have argued that 'by increasing the practical challenges while simultaneously reinforcing the psychological burdens associated with abortion care, these laws may have a negative impact on the abortion provider workforce'.

\section{TRAP LAWS AND ABORTION RESTRICTIONS}

Roe vs. Wade, the 1973 landmark legal case involving abortion in the United States, recognised that the constitutional right to privacy extends to a woman's right to make her own personal medical decisions, including those concerning abortion. Despite this, provider restrictions and clinic requirements are commonplace. Since 1973, individual states have singled out abortion provider practices and imposed burdensome requirements that are not imposed on other medical practices. These TRAP Laws (Targeted Regulation of Abortion Providers) go beyond what is necessary for patient safety (Guttmacher Institute, 2018a) and can be difficult and costly for clinics to observe. According to Medoff (2009: 227), TRAP laws 'impose on abortion providers medically unnecessary and burdensome plant and personnel requirements that regulate wide-ranging aspects of abortion providers' operations'. Furthermore, some TRAP laws apply state standards for ambulatory surgical centres (ASCs) to abortion clinics, even though clinics do not provide the same services that ASCs provide such as higher levels of sedation (Guttmacher Institute, 2018b). In some states, TRAP laws extend to locations and physicians' offices where only medical abortion is administered (Grossman et al., 2014; Guttmacher Institute, 2018b), further restricting abortion access. Other restrictions include medically unnecessary requirements like mandatory waiting times, hallway width stipulations and admitting privileges at a local hospital even though abortion providers often do not meet the minimal annual patient admissions that some hospitals require ${ }^{1}$ (Grossman et al., 2014; Guttmacher Institute, 2018b; Medoff, 2009). Transfer agreements with a local hospital within a set number of miles are required in eight states ${ }^{2}$ (Guttmacher Institute, 2018a), further restricting access for providers, including the clinic in this study. The American College of Obstetricians and Gynecologists (ACOG) has expressed concern regarding these restrictions and their impact on the patient and the physician-patient relationship (ACOG, 2014; Grossman et al., 2014; Mercier et al., 2015). In sum, abortion provision in the United States, as Mercier et al. (2017: 78) have noted, 'has become a dance between lawmakers and providers'.

TRAP laws and abortion restrictions disproportionately affect low-income women (ACOG, 2014; Grossman et al., 2014) and women of colour. In 2014, $75 \%$ of abortion patients were poor (income below the poverty level of $\$ 15,730$ for a family of two) or of low-income (having an income of $100-199 \%$ of the federal poverty level) (Guttmacher Institute, 2018b; Jones and Jerman, 2017). Black women are overrepresented among abortion patients in having the highest abortion rate of 27.1 per 1000 compared to White women's 10.0 per 1000 between the years 2008 to 2014 (Jones and Jerman, 2017). Jones and Jerman (2017) have noted that this overrepresentation may reflect a disproportionate share of women of colour residing in states where "abortion restrictions successfully

\footnotetext{
${ }^{1}$ Hallway stipulations and room width requirements are examples of a physical plant TRAP laws that make compliance costly and at times, almost impossible for abortion clinics to meet, leading to clinic closures. Similarly, admitting privilege requirements "mandate that clinicians performing abortions have admitting privileges at a local hospital, even though complications from abortion that require are so rare, so abortion providers are unlikely to meet minimum annual patient admissions that some hospitals require", causing another barrier for patients seeking abortion care. (https://www.guttmacher.org/ evidence-you-can-use/targeted-regulation-abortion-providers-trap-laws)

2 Transfer agreements, according to the Guttmacher Institute, require that an abortion clinic "maintain relationships with local hospitals, provisions that add nothing to existing patient protections while granting hospitals effective veto power over when an abortion provider can exist." Furthermore, these requirements do little to improve patient care, but are another example of mandates that may be impossible for clinics to observe. (https://www.guttmacher.org/state-policy/explore/targetedregulation-abortion-providers)
} 
reduced access to care" (1908). When a clinic closes because it is unable to meet state requirements—often because of cost-patients must travel greater distances, thereby incurring additional costs that can include childcare, hotel stays, and unpaid time off from work. This can impact a patient's ability to pay monthly bills such as rent, groceries, and utilities (Jones, et al., 2013). Patients may find themselves chasing the cost of their abortion when they do not have funds readily available (Grossman et al., 2014; Guttmacher Institute, 2018b; Medoff, 2009). Abortion providers feel that complying with TRAP laws are burdensome for patients as well as clinic staff, potentially harmful to patients and can interfere with the trust and rapport in the patient-physician relationship (Mercier et al., 2015; Weinberger et al., 2012). Moreover, TRAP laws are designed not just to make access to abortion difficult for patients seeking care, but they can also impact on the number of providers within a state or region (Medoff, 2009; Mercier et al., 2015). Approximately 60\% of abortion clinics in the United States are independently owned, making them especially vulnerable to TRAP laws. Since 2012, 145 of 510 independent clinics have closed (Madsen et al., 2017).

Ever changing abortion restrictions also affect patient access. In 2017, 19 states adopted 63 new abortion access and rights restrictions, the largest number of restrictions enacted in one year since 2013 (Nash et al., 2018). In 2017, 29 of the 50 states were categorised as 'hostile' or 'extremely hostile' to abortion rights and 29 states have 'enacted at least two abortion restrictions that are not based on scientific evidence' (Nash et al., 2018: n.p.). Other aggressive efforts to limit abortion include so-called heartbeat bills that ban abortion if six weeks have elapsed since the woman's last menstrual period even though many women may not know they are pregnant at such an early stage (Filipovic, 2019). Since 2011, 162 abortion providers have shut down or have stopped offering services with only 21 clinics opening during that time (Deprez, 2016), indicating that access to a local abortion clinic is becoming increasingly restricted for patients in the USA.

\section{STATE SPECIFIC RESTRICTIONS AND TRAP LAWS}

To examine the impact abortion restrictions and TRAP Laws have on non-physician staff and volunteers, indepth interviews during the early spring and summer of 2018 were conducted with eleven $(n=11)$ clinic nurses, patient advocates, and volunteer clinic escorts at an independently owned Midwestern abortion clinic in the United States. Based in a state that is deemed extremely hostile to abortion access by the National Abortion Rights Action League (NARAL), a non-profit organisation that engages in political action and advocacy efforts to oppose restrictions on abortion while also increasing access to abortion (NARAL, 2020). The city in which the clinic is based has approximately 300,000 residents, and a poverty rate of 33\% (the second highest in the state). The clinic performs between 800 and 1100 medical and surgical abortions annually. Study participants estimated that about half of the patients they serve are women of colour, of low income, and need financial assistance via a national or local abortion fund to pay for services. Additionally, this state has seen a decline in clinics in recent years.

There are several TRAP laws which the clinic in this study had been forced to comply with, such as adhering to structural standards comparable to those for ASCs and acquiring a transfer agreement with a local hospital within 30 miles of the clinic. Transfer agreements, according to Jerman et al., (2017: 97) 'mandate a contractual arrangement with a local hospital to transfer patients in the event of a complication even though no hospital may refuse emergency care'. Furthermore, the growth in faith hospitals across the United States directly impacted the clinic in this study. Uttley et al. (2016) found that faith hospitals operate one in five hospital beds in the United States and $70 \%$ of those hospitals are Catholic affiliated. Catholic institutions are required to follow the Ethical and Religious Directives for Catholic Health Care Services (ERDs) and this prohibits clinicians from providing services such as abortion, contraception, male and female sterilisation, and, in some cases, treatment during miscarriage (Freedman and Charo, 2018). Catholic hospitals vastly outweigh Secular hospitals in the city where the clinic is located and this has made obtaining a transfer agreement with a local hospital exceedingly difficult, as Catholic affiliated hospitals in the area would not participate in the transfer agreement process due to the ERD.

Additionally, there are many abortion restrictions enacted with which clinic staff must comply including: a 24hour mandatory waiting period; biased state-directed counselling that aims to discourage patients from having an abortion; limitations on abortion medical insurance coverage for public sector employees to life endangerment, rape, or incest; and parental consent for minors (Guttmacher Institute, 2018a). Furthermore, patients receive state mandated counselling designed to discourage abortion at their initial visit. The patient is then required to wait 24 hours before their procedure, requiring at minimum, two visits to the clinic. Proponents of mandatory counselling and waiting period laws argue that the state has a duty to ensure that a woman has ample time to make a decision about her options after being given information about her pregnancy and abortion. Pro-choice campaigners who oppose waiting periods and state mandated counselling argue that these laws are unnecessary since physicians obtain informed consent before all procedures and further believe that these waiting periods and counselling 'serve no medical purpose and are a ruse to decrease the accessibility of abortion' (Joyce et al. 2009: 3). 
Compulsory counselling increases the cost of an abortion if the patient must take time off from work, arrange childcare, or stay overnight (Jerman et al., 2017; Joyce et al., 2009). This requirement may also increase the likelihood of patients travelling outside of the state to avoid compliance with the law (Joyce et al. 2009). A study of the mandatory counselling and waiting period statute in Mississippi (24 hours prior to induced termination) found a 'decline in the abortion rate, a rise in abortions obtained out-of-state, and an increase in the proportion of second trimester abortions' Joyce et al., 2009: 15; also see Althaus and Henshaw 1994; Joyce et al., 1997; Joyce and Kaestner, 2000). Additionally, waiting periods may lead to a delay in appointment times making abortion more expensive, particularly once the patient reaches the second trimester (Jones and Jerman, 2017).

Thirty-seven states, including the state in this study, have laws that require an 'unemancipated, pregnant minor to either get her parents' consent to the abortion or to notify them of the decision to seek an abortion' (Humphrey, 2017). These parental involvement laws do not infringe on the constitutional rights of a minor if a judicial bypass proceeding is available, set forth by the US Supreme Court in Bellotti v. Baird (1979) according to Humphrey (2017). With the implementation of the parental notification law in 2000, Texas saw a decline in abortion rates, a rise in birth-rates and an elevated likelihood of 'minors obtaining an abortion after 12 weeks' gestation' (Joyce, 2010: 168). In 1992, the landmark Supreme Court case Planned Parenthood of Southeastern Pennsylvania v. Casey, stated that mandatory counselling, waiting laws, and parental consent for minors were constitutional (Planned Parenthood, 2020). According to Medoff (2009: 225), this ruling gave states 'considerable latitude to enact laws restricting a woman's access to abortion [and] required lower courts to interpret whether an enacted restrictive state abortion law imposes an undue burden on women's access to abortion.

This study adds to the discussion surrounding abortion provider challenges in the United States under a vocal, anti-abortion presidential administration. The perspectives of clinic nurses, patient advocates, and volunteers are crucial as clinics cannot function effectively without staff, many of whom stay at their clinics for years. Furthermore, volunteers have come to play an increasingly important role in mitigating the stresses of patient experiences as some clinics are unable to pay staff to perform that work. According to Debbink et al. (2016: 1823), 'relatively little is known about the factors that influence either physicians' or non-physicians' decisions to participate in abortion care or affect their tenure in the abortion care workforce'. These interviews provide experiential evidence of the impact of TRAP Laws and abortion restrictions for non-physician employees and volunteers, emphasising women's voices in the debates surrounding abortion and the lived consequences of the continuous assaults on Roe vs. Wade.

\section{METHODS}

After the Institutional Review Board (IRB) approval was granted, interviews were conducted with all nonphysician staff and volunteers at the clinic in this case study. Following Sandelowski (2000), purposive sampling was used to obtain cases deemed information rich for its purposes. This involved selecting participants 'who share particular characteristics and have the potential to provide rich, relevant and diverse data pertinent to this study' (Tong et al., 2007: 352). These characteristics included being a non-physician employee or volunteer at the abortion clinic in this study. These in-depth interviews covered a range of expertise and experience, offering rich insight into a small-scale study with a particular abortion provider at a time of intense anti-abortion activism.

Participants were recruited via the clinic manager and were provided with information about this study, including a copy of the IRB approval letter, a letter describing the study, a site permission letter from the clinic manager, and the researcher's contact information. Individual interviews, as opposed to focus groups, were used in this study in order to 'explore the experiences of participants and the meanings they attribute to them' (Tong et al., 2007: 351). All interviews were conducted face-to-face at a location of the participant's choosing. Each interview was tape recorded, lasted between 75 and 95 minutes, and was transcribed verbatim within 4 days of the interview. Additionally, the researcher took field notes during each interview in order to 'maintain contextual details and nonverbal expressions for data analysis and interpretation' (Tong et al. 2007: 356).

Eleven volunteers and employees $(\mathrm{n}=11)$ were interviewed for this case study. All patient advocates and nurses were interviewed $(n=6)$, in addition to four volunteer clinic escorts $(n=4)$, and the clinic manager $(n=1)$. The volunteer coordinator helped to identify patient escorts for this study who regularly escort patients to and from the clinic building at least once a month. Patient advocates spend the most time with patients and their roles include setting appointments; assisting with the National Abortion Fund (NAF) and gaining local abortion funding assistance to those who cannot afford their procedures; filing paperwork; answering the phone on the days the clinic is closed; providing state mandated counselling for patients on their first visit to the clinic; sorting foetal tissue after procedures to ensure all tissue has been removed; and providing patients with emotional support. The nursing staff assist the physician during the abortion, and the recovery room nurse monitors patients after their procedures. Clinic escort volunteers spend their time in the parking lot at the clinic, providing a physical barrier between patients and protesters, often using umbrellas to shield clients. The clinic manager oversees the entire 
clinic and assists nurses, patient advocates, escorts, and the doctor whenever necessary. Additionally, the clinic manager corresponds closely with local police and trains new employees. All participants self-identified as female and were between ages of 23 and 67. Ten identified as white $(n=10)$ and one participant identified as Latina $(n=1)$. The majority of the participants had a college, professional, or nursing degree $(n=10)$. Three of the participants shared their personal abortion stories. Employment time at the clinic ranged from 8 months to 5.5 years. Volunteer duration ranged from 1.5 to 3 years.

Participants were interviewed using a semi-structured interview guide (Brinkman and Kvale, 2014; Sandelowski, 2000), with the researcher using open-ended questions (Tong et al., 2007), and, when appropriate, asking probing questions to further encourage more in-depth data. This allowed for participants to speak at length. The interview guide asked participants their demographic information, then moved onto their motivations, experiences, and any challenges they experienced at the clinic. At the end of each interview, the researcher verbally summarised the interview with the participant to ensure accuracy. Several participants made corrections to the researcher's summary. The researcher contacted three participants after their interview to ask for additional information (e.g. more detail about specific protesters or dates regarding the transfer agreement process).

A case study approach was adopted for this study in order to develop an in-depth understanding of the specific challenges experienced by non-physician staff and employees at the abortion clinic. Creswell and Poth (2018: 96) posit that case study research is defined as a qualitative approach in which the investigator explores a real-life, contemporary bounded system . . . through detailed, in-depth data collection involving multiple sources of information'. Bogdan and Knopp-Biklen (2007: 59) assert that a case study is 'a detailed examination of one setting, or a single subject, a single depository of documents, or one particular event'. Additionally, Creswell and Poth (2018: 97) have argued that the case study allows researchers to study 'current, real-life cases that are in progress so that they can gather accurate information not lost by time'.

To ensure confidentiality and based on IRB stipulations, the name of the state, city, clinic, and location have been omitted. Pseudonyms have been assigned to all participants and no personal identifying information has been offered. There are no references to a particular hospital or to providers' names.

\section{DATA ANALYSIS}

Qualitative content analysis was used to analyse the data. Sandelowski (2000: 338) has argued that 'qualitative content analysis is data-derived' where codes are 'systematically applied but have been generated from the data themselves in the course of the study'. Furthermore, qualitative content analysis is simultaneously reflexive and interactive as 'researchers continuously modify their treatment of data to accommodate new data and new insights about those data'. Qualitative content analysis is the 'least interpretive of the qualitative analysis approaches in that there is no mandate to re-present the data in any other terms but their own'.

After each interview was transcribed, the transcripts were read so that the researcher could familiarise herself with the data. All transcripts were read twice, in order to provide a close reading of each interview. During this time, the researcher took notes on any interesting and relevant words, sentences, and responses from the participants. Initial codes were formed by noting regularities, patterns, and repeated topics the data covered (see Creswell and Poth, 2018). After another close reading of the data, relevant responses were grouped into broader, recurring themes, which were defined as the researcher progressed though the analytic process. These themes were then integrated into an in-depth description of the participants' experiences, which included relevant quotes from each interview that supported the emerging themes and represented common experiences (see Bodgan and KnoppBiklen, 2007; Merriman and Tisdale, 2016; Thomas, 2006). Data has been arranged from the most prevalent theme to the least prevalent one, as suggested by Sandelowski (2000), starting with the transfer agreement process, which was the most pressing issue for participants at the time of their interviews. Given the relatively small sample size in this study, no qualitative software was used for this analysis. Three main themes emerged from the data regarding participants' experiences of negotiating changing abortion policies at this clinic: having a transfer agreement in place does not mean the clinic will stay open; protesters are a nuisance, but other clinics have it worse; and a positive relationship with local police mitigated safety concerns.

\section{Having A Transfer Agreement in Place Does Not Mean the Clinic Will Stay Open}

All participants had been involved, to varying degree, in a recent arduous transfer agreement process. For several years the clinic had a transfer agreement with an out of state hospital located 55 miles away. However, in 2015, newly written state legislation stated that the receiving hospital must be located not more than 30 miles from the clinic with study participants noting that this new law was written specifically for their clinic. This put the clinic out of compliance for almost three years, leaving the fate of this clinic in a state of flux. Participants stated that they worried for patient access, as their clinic could be closed with little notice, leaving patients to travel further distances and incurring higher costs for their abortions. In the spring of 2018, one of the largest medical facilities 
in the area agreed to sign a transfer agreement. This was met with hostility from local anti-choice organisations who protested outside their largest hospital. They also rented out seven billboards around the city, shaming the organisation for their participation in the 'murder of children', asking city residents to boycott these facilities and pleading with the hospital board members to reconsider the transfer agreement which was valid for one year.

The participants felt that the transfer agreement was just one of the many hurdles that the clinic will continue to face. Katie, a 24-year-old patient advocate stated,

I don't think we are ever safe . . because people aren't going to stop trying to chip away. They are going to keep pushing, they are going to keep going until it's [abortion] illegal.

Patient advocate, Taylor (23) agreed, saying:

I think there will always be lasting effects from it. It's only signed for a year . . . they can review it and decide not to sign it ... . it definitely isn't an issue that's going away, we are going to have to keep having this conversation.

Operating room nurse, Rachel (67), added:

I think the health department is going to find whatever is wrong with us, you know? All those people that govern people, that are checking up on you ... they are going to find something wrong, and it's stupid shit. And that's what gets infuriating.

Recovery room nurse, Rena (59), agreed that the next hurdle the clinic will face is just around the corner, saying that she believes TRAP laws are:

just going to be the nature of the abortion business until hell freezes over... I don't know that we are ever going to get to a place that I think is ideal, which is abortion on demand. I don't know if this country is ready for that. It's a shame, it should be.

Escort volunteer coordinator, Carrie (30), expressed her anger that the transfer agreement took as long as it did:

We are supposed to be nice about [hospital name omitted] but fuck [hospital name omitted]. It's been five years since [the other abortion clinic; name omitted] closed down, the loss of jobs, the loss of access for patients ... the demand for abortion hasn't gone down in [city name omitted] and it's still being served by one clinic when we have enough demand for two clinics . . . it was bittersweet when it [the transfer agreement] was signed.

Sarah (32), who had been managing the clinic for three years, recalled a recent five-month period when the clinic had no transfer agreement because none of the mostly religiously affiliated six hospitals within a 30-mile radius would agree to sign an agreement. Sarah discussed the strain of working in abortion care: the difficulties of which she had to negotiate each day while worrying about how the clinic would be able to meet their patients' needs, in addition to making sure the clinic was appropriately staffed. She stated:

We didn't know if we were going to be open, we were constantly living under this threat of closures and restrictions and it was really hard. It was a roller coaster... There were times when we thought we were going to have to stop doing abortions on Friday and we found out on Tuesday, so we added Wednesday and Thursday... I had to make sure we had a doctor, that we had staff. And it was months of that which is exhausting.

During the time when the clinic was unable to perform surgical abortions ${ }^{3}$ in early 2018, Sarah recalled having to turn patients away whose pregnancies were further along than 10 weeks. One patient Sarah spoke to was in a 'heart-breaking situation', as she was just past the 10-week mark and could not be seen at the clinic. Sarah referred the patient to an out-of-state clinic. Three weeks later, the patient called back saying that she was unable to get an appointment at the out-of-state clinic since the waiting list was several weeks long. Thankfully, Sarah's clinic was able to perform surgical abortions again. However, she recalls:

the patient was 13 weeks pregnant ... and she's struggling to find a way to get to [city name omitted] to get this thing she clearly wants, she does not want to be pregnant, and she's stewing in her own thoughts.

\footnotetext{
${ }^{3}$ The participants in this study used the term 'surgical abortion' at the time of their interviews. See Regina Mahone Notes on Language: Why we stopped using 'surgical abortion' at Rewire.News for an update in industry standard language.
} 
She's an emotional mess and she finally made it into the clinic to see us. She was 14 weeks by the time she got her abortion and it cost her $\$ 700$. It's just crazy she suffered because the state made her suffer. That's what they want. They don't give a shit about women.

Sarah discussed the frustrations of trying to remain open in an anti-abortion state saying:

If we lose [clinic name omitted] [state and city name omitted] will have no clinic. We've lost over half the clinics in the state since [state Governor name omitted] has been elected, so it's real. It's shocking and it's getting worse.

For Sarah, working at the last abortion clinic in her city was a job she took seriously and was passionate about. She felt it was her duty to protect women's access to abortion, which is why she continued to work at the clinic, despite the almost constant stress, lack of health care and retirement benefits, low pay, job instability and the neverending stream of TRAP laws and restrictions the clinic must adapt to. Working at the clinic, she said, is life or death' and she stated that if the clinic closes, the city will 'lose vital heath care resources'.

As illustrated by the participants, obtaining a transfer agreement was a stressful and prolonged process and one the participants expect to face again. Participants felt that while obtaining the transfer agreement was 'a win' their relief was short lived. They were aware of a second clinic in the city that had to closed because of a problem over the transfer agreement and understood the very real possibility of this happening to their clinic, thereby fuelling their fears of closure. Sarah estimated that the clinic spent 'tens of thousands of dollars on legal fees' during the five-year transfer agreement process, noting that those funds could have been used for much needed security as well as structural and medical equipment improvements at the clinic. All participants were aware that TRAP laws and abortion restrictions are costly and that clinic owners struggle to afford the changes these restrictions mandate. The clinic may be forced to close its doors given these insurmountable costs, causing a major disruption for women seeking abortion services in this city.

\section{Protesters Are A Nuisance, But Other Clinics Have It Worse}

In addition to adhering to scores of TRAP laws and state mandated abortion restrictions, one of the most acute challenges this clinic faced were anti-choice protesters. As the only abortion clinic in the city, there is a concentration of dedicated anti-abortion protesters who spend money and time protesting. Participants stated that this harassment impacted negatively on patients and at times, could deter them from seeking abortion care. Taylor stated:

If I was a patient going to the clinic for the first time . . I would be disheartened if they tried to follow me and talk to me through my car. We're just women trying to get informed of our options.

As a patient advocate, Katie saw a direct connection between the protesters and police outside of the clinic and the shame and confusion many of her clients felt, leading many of them to question the legality of the procedure they were seeking and the legitimacy of the doctors at the clinic. Katie stated that patients often say things like "The doctors are real doctors, right? And they went to medical school, right? And this is legal, right?" Katie felt that some clients are so distressed and anxious to end their pregnancies they are willing to risk the possibility that the medical professionals they are seeing may not be licensed, could cause irreversible harm and that they could be participating in an illegal activity by having an abortion. This, she added, is how 'desperate some women and girls are to terminate their pregnancies'.

Several participants wondered how many patients got to the clinic, saw protesters and police and decided to leave. Katie stated that patients often ask her if the protesters are allowed to touch them, follow them off the property, or talk to them, saying:

patients are really scared of the protesters. Any type of medical procedure, they are already nervous, [but] the protesters make them uncomfortable. They make them scared, [as in] I-can't-go-in-there scared.

Katie also noted that the protesters routinely film patients going into the clinic and post the videos on social media, adding greatly to patient distress. Sarah noted that another popular tactic anti-choice organisations in the area employ is to make fake appointments thereby making it more difficult for legitimate patients to be seen. Sarah and Katie both noted that they expect a certain number of the clinics' daily appointments to not show up because of this underhand scheme, stating that clinic staff 'just work harder' to meet patient demand.

Employees and volunteers had several stories of hostile or uncomfortable run-ins with anti-choice protesters. However, all agreed that other clinics in the state experience more intense and malicious harassment, making many of the participants feel 'lucky'. Most of the participants described their regular anti-choice protesters as 'lazy', and 
as 59-year-old Kathleen, a patient escort, stated, they are led by a group of 'old, white Catholic men'. Patient advocate, Paula (41), shared her insight when she described the protesters:

I don't worry about protesters. They are just the physical representation of all of the legislation we deal with. I'm pretty confident that protesters are people who lack community and protesting helps to create community and give meaning to their life.

For Paula, trying to understand the motivations of protesters may be a way for her to effectively cope with having to walk through vocal, persistent protesters every time she goes to work. Additionally, Paula viewed the protesters as tangible, concrete examples of the barriers patients face when they are trying to access abortion services at this clinic, thereby providing a visual example of the controversy that still surrounds this medical procedure. These barriers, she argued, are further reinforced by TRAP laws and state mandated abortion restrictions that make it difficult for independent clinics to stay open and for patients to access services.

While all the participants felt that the protesters were a nuisance for employees, volunteers, and patients, they believed that their clinic 'didn't have it as bad as other ones' in the state and around the country where anti-choice protesters routinely have larger groups of people and audio equipment, as Taylor and Carrie stated. Participants understood that negotiating the barriers presented by protesters was an expected part of their job and they had learned not to engage with them, even when protesters demonstrated knowledge of private, personal information. Participants described harassment that included protesters reciting home addresses, spouse/partner/child names, taking pictures of license plates and the use of recording devices. One participant recalled a protester yelling about the suicide of a former employee's husband, adding that 'nothing is off limits' when it comes to protesters harassing the clinic's employees and volunteers. Participants reported that social media harassment was common, as well as seeing their pictures and names on anti-choice Facebook pages where they are commonly labelled as 'murderers'. Despite these attempts at intimidation, few participants felt that they were in any real danger. Several participants felt that their protesters were becoming 'more emboldened' as state restrictions became more stringent, thereby legitimising protester beliefs that abortion should be prohibited in this state. In sum, this harassment was not a deterrent for the participants in this study who felt that helping patients through what may be a difficult situation was more important than any harassment they are forced to endure at the clinic.

\section{A Positive Relationship with Local Police Mitigated Safety Concerns}

Most of the participants felt safe at their clinic and reported that they took few safety precautions both at work and outside of work. However, all participants recognised that the clinic needed police presence because of the highly contested nature of abortion work that leads some individuals to act violently. Carrie felt that TRAP laws and state abortion restrictions were fuel for anti-choice protesters, providing them with more evidence for the abolition of abortion. Recent anti-choice gains by President Trump and state government officials, she said, were encouraging an increase in protester activity since protesters felt that they had more political backing and were feeling 'emboldened' in their efforts to close the clinic. Despite this increase in protester activity and an awareness of violence at other US clinics, only two employees, Katie and Emily, stated that they 'risked their life every time [they walked] through that door'. In contrast, Sarah communicated that the clinic now "has 'no trespassing' signs, but as far as my personal safety there's nothing that I do". Rachel agreed, saying, "I never have really [worried] even when you hear about people bombing and shooting up [clinics]. I don't think it's ignorance, I just don't feel that way." Mary added, "Every once in a while I think how easy it would be for someone to drive by and do something," but this possibility was not enough to deter her from escorting patients into the clinic several days a month. The participants stated that their positive relationship with the local police contributed to their feelings of safety, despite the increase of protesters at their clinic. Sarah stated:

We have a really good relationship with our officers who come in so I'm so thankful for that, because that's not the case in a lot of places including [city name omitted]; they have a terrible relationship with their officers.

Katie, who worked at a sister clinic in another city for almost a year, agreed, adding:

There is a good police force in [city name omitted] which I know makes some people really uncomfortable, understandably. I do kind of like it though ... they come into the clinic and they talk to us and they are pro-choice and it makes me feel a little more comfortable. That did not happen at [clinic name omitted].

Katie's statement indicates that employees and volunteers must attempt to balance clinic safety with remaining cognisant of how police presence may add an additional level of unease for patients. While police presence is, unfortunately, a necessity at many abortion clinics in the United States, this may contribute to patient distress while 
they are at the clinic, especially for communities who are targeted by police and who experience harassment and violence.

Study participants were grateful for the relationship they had with the local police and many noted that some clinics are not fortunate enough to have the police support on which the clinic relies. Most of the participants shared stories of police being called in to handle a potentially dangerous situation, almost always related to antichoice protesters. All participants stated that local police were 'wonderful' and handled these situations 'quickly' and 'respectfully'. Three participants named a specific officer, stating that he stays up-to-date on changes in state laws regarding abortion access, which participants saw as an indication of his support for their work. This officer was especially adept at managing the well-known 'big name' abolitionists who make a yearly pilgrimage to the clinic, and who often attract larger crowds of 'antis'. Clinic escort Paula recalled abortion abolitionist Cal Zastrow ${ }^{4}$ being arrested outside her clinic for trespassing when he stood by the recovery room window with a bullhorn, 'screaming about Jesus and murder' while patients were recovering from their procedures.

The clinic hires off-duty police officers as additional security for the two to three days a week the clinic is open, indicating that in this anti-abortion state, statutory state-funded services appear to collaborate with the clinic and it is this strategy that affords protection and security. Several participants felt that this helped the officers to be more personally invested in the clinic and its safety, perhaps partially because of an economic relationship between providers and police who depend on the extra pay they earn by protecting the clinic. This relationship may help to ensure that the clinic in this study does not experience the same levels of harassment and violence as do other clinics.

\section{DISCUSSION}

This study adds to the understanding of challenges that non-physicians face in the United States under a vocal, anti-choice presidential administration. The importance of political discourse must be taken into account when examining abortion since legality does not ensure equal access to abortion care. The community-based, independently owned abortion clinic in this study faced challenges by complying with burdensome and costly TRAP laws put into place by anti-choice state legislators. In the spring of 2018 , the clinic was unable to perform surgical abortions for three weeks because of a Health Department licensing issue, which one participant saw as a 'symptom' of a TRAP law. Participants felt that patient care was negatively impacted by this restriction, women were being harmed and that low-income patients were affected the most since they had fewer options available to them. In order to help remedy this, the clinic provided $\$ 25$ gas cards to patients to help defray travel costs to their sister clinic located 150 miles away. Patient advocates experienced the added desperation patients felt when the clinic was unable to provide surgical abortions and they articulated fears that the clinic would close. All participants felt that low-income women would be impacted the most by a clinic closure, and many participants regularly donated money and volunteered with a local abortion fund that helps women access money for their procedures. Similar to the findings of Mercier et al. (2017), the participants in this study often took on additional financial and time-related burdens to meet patient demands without increasing the cost of their abortion services. Additionally, the participants in this study understood the 'amalgamation of barriers and consequences' (Jerman et al., 2017: 95) that the combination of TRAP laws and abortion restrictions create for patients, making care difficult and expensive.

The participants learned to tolerate anti-choice protesters as part of working in abortion care and believed that the regular protesters were not particularly threatening. However, the participants noted that protesters had become more emboldened recently, a nationwide trend reported in 2017 (Lovan, 2018). In the spring of 2019, the clinic was vandalised on two separate occasions when windows were broken, several threatening letters were sent to the clinic, and a bomb threat was called in. Participants felt this shift came about because of the current political climate and recent legislation victories by anti-choice groups. Attitudes towards personal safety may change if this clinic experiences more hostile protester activity, as reported by the 2017 Feminist Majority Foundation Clinic Violence Survey.

A positive relationship with local police helped participants to feel safer at their jobs, supporting findings conducted by the Feminist Majority Foundation (2017). However, participants did note that police presence is more likely to cause an additional layer of stress and uncertainty for their patients, causing some to question the legitimacy of abortion procedures. Should an increase in police presence become necessary, patient access may be further impacted.

\footnotetext{
${ }^{4}$ Zastrow is the co-founder of Personhood USA (a pro-life organisation based in Denver, Colorado) whose purpose is to support local pro-life organisations around the United States with training, ballot initiatives and protesting: http://prolifeprofiles.com/zastrow.
}

(C) 2020 by Author/s 


\section{LIMITATIONS AND FUTURE RESEARCH}

Although the results of this study provide empirical evidence of the challenges nurses, patient advocates and volunteers must negotiate at an abortion clinic in an abortion-hostile state with many restrictions, there are several limitations to consider. First, most of the participants in this study are ethnically white women and their experiences may be vastly different from those of people of colour, especially regarding the regular presence of police at the clinic. While the participants appreciated having off-duty police officers stationed in their parking lot, clinic employees at other clinics who are not white may feel differently. Furthermore, while all nurses, patient advocates, and regular clinic escorts were interviewed, the sample size for this clinic is modest and fairly homogeneous in regard to race/ethnicity, sex, gender identity, socioeconomic status, and education. A survey of existing reproductive justice literature indicates a need for more demographic information on non-physician staff and volunteers since the researcher was unable to find nation-wide demographic information on this population. This area of inquiry would benefit from more studies conducted in other states and at other clinics in order to better understand the challenges experienced by this group. Lastly, it is important to note that recall bias on the part of participants and researcher bias when identifying and coding likely impacted the results in the study, despite efforts to minimise these biases.

\section{CONCLUSION}

As independently owned clinics continue to face burdensome restrictions, many clinics will struggle to stay open. Clinic closures will be devastating for patients since this will limit abortion access to them, create fragmented patient care and produce greater numbers of providers practicing in restrictive environments (see Mercier et al., 2017). The consequences of ignoring the experiences and sacrifices of non-physician staff and volunteers will have a direct impact on how clinics are able to function. Without their contributions, clinics will continue to close and patient access will be negatively affected as it is often non-physician staff who spend the most time with patients. Additional studies that focus on non-physician staff experience should be conducted in the hope of further informing the public and gaining its collective support for abortion advocates and legislators. By focusing on the experiences of non-physician employees and volunteers at individual clinics, researchers are making (women's) invisible labour visible, increasing our understanding of the particular issues non-physician staff and volunteers face, the impact of this on patient care and the preservation of abortion access. In an example of women's work being undervalued and made invisible, Mercier et al., (2017: 78) have noted that "just as the work of women can often be invisible, work undertaken for women can be similarly obscured", as indicated in this study.

In understanding non-physician challenges negotiating TRAP laws, abortion restrictions, and the invisible labour that accompanies adherence to these laws, clinics can work not only to better serve their patients, but better serve the foundation of their clinic, the staff, and the volunteers who show up year after year and who are on the frontlines of providing care for patients.

\section{REFERENCES}

American College of Obstetricians and Gynecologists (ACOG). (2014). Committee opinion no 613: Increasing access to abortion 2014. Available at: https://www.acog.org/-/media/Committee-Opinions/Committee-on-HealthCare-for-Underserved-Women/co613.pdf?dmc=1\&ts=20180910T1336051837 (Accessed 08 September 2019)

Althaus, F. A. and Henshaw, S. K. (1994). The effects of mandatory delay laws on abortion patients and providers. Family Planning Perspectives, 26(5), 228-231.

Andaya, E. and Mishtal, J. (2016). The erosion of rights to abortion care in the United States: A call for a renewed anthropological engagement with the politics of abortion. Medical Antbropology Quarterly, 31(1), 40-59.

Berer, M. (2017). Abortion law and policy around the world: In search of decriminalization. Health and Human Rights Journal, 19(1), 13-27.

Bogdan R. C. and Knopp Biklen, S. (2007). Qualitative Research for Education: An introduction to theories and methods. Boston, MA. Pearson.

Brinkman S., and Kvale S. (2014). InterViews: Learning the craft of qualitative research interviewing (3rd ed.). Thousand Oaks, CA: Sage.

Britton, L. E., Mercier, R. J., Buchbinder, M., and Bryant, A. G. (2017). Abortion providers, professional identity, and restrictive laws: A qualitative study. Health Care for Women International, 38(3): 222-237.

Cockrill, K. and Nack, A. (2013). 'I'm not that type of person': Managing the stigma of having an abortion. Deviant Behavior, 34(12), 973-990. 
Creswell, J. W. and Poth, C. N. (2018). Qualitative Inquiry and Research Design: Choosing among five approaches (4th ed.). Thousand Oaks, CA. Sage.

Debbink, M. L. P., Hassinger, J. A., Martin, L. A., Maniere, E., Youatt, E., and Harris, L. H. (2016). Experiences with the providers share workshop method: Abortion worker support and RESEARCH in tandem. Qualitative Health Research, 26(1), 1823-1837.

Deprez, E. (2016). Abortion clinics are closing at a record pace. Available at: https://www.bloomberg.com/news/ articles/2016-02-24/abortion-clinics-are-closing-at-a-record-pace. (Accessed 22 July 2019).

Feminist Majority Foundation. (2017). 2016 national clinic violence survey. Available at: http:/ feminist.org/antiabortion-violence/images/2016-national-clinic-violence-survey.pdf. (Accessed 18 May 2019).

Freedman, L. and Charo, R. A. (2018). When conscience calls for treatment: The challenge of reproductive care in religious hospitals. National Academy of Medicine. https://doi.org/10.31478/201804c. (Accessed 22 June 2020).

Filipovic, J. (2019). Trump's anti-abortion agenda emboldened an all-out war on women's rights in dozens of states. Available at: https://www.nbcnews.com/think/opinion/trump-s-anti-abortion-agenda-emboldenedall-out-war-women-ncna994661. (Accessed 28 April 2019).

Grossman, D., White, K., Hopkins, K., and Potter, J. E. (2014). The public health threat of anti-abortion legislation. Contraception, 89(2), 73-74.

Guttmacher Institute. (2018a). Regulation of abortion providers, 2018. Available at: https://www.guttmacher.org/state-policy/explore/targeted-regulation-abortion-providers. (Accessed 15 July 2019).

Guttmacher Institute. (2018b). Targeted regulation of abortion providers (TRAP) Laws. Available at: https:/ / www.guttmacher.org/ evidence-you-can-use/targeted-regulation-abortion-providers-trap-laws. (Accessed 15 July 2019).

Harris, L. H., Debbink, M., Martin, L., and Hassinger, J. (2011). Dynamics of stigma in abortion work: Findings from a pilot study of the Providers Share Workshop. Social Science \& Medicine, 73(7), 1062-1070.

Harris, L. H., Martin, L., Debbink, M., and Hassinger, J. (2013). Physicians, abortion provision and the legitimacy paradox. Contraception, 87(1), 11-16.

Humphrey, W. A. (2017). Two-stepping around a minor's constitutional right to abortion. Cardozo Law, 38, 17691815.

Jerman, J., Frohwirth, L., Kavanaugh, M. L., and Blades, N. (2017). Barriers to abortion care and their consequences for patients traveling for services: Qualitative findings from two states. Perspectives on Sexual and Reproductive Health, 49(2): 95-102.

Jones, R. K., and Jerman, J. (2017). Population group abortion rates and lifetime incidence of abortion: United States, 2008-2014. American Journal of Public Health, 107, 1904-1909.

Jones, R. K., Upadhyay, U. D., and Weitz, T. A. (2013). At what cost? Payment for abortion care by U.S. women. Women's Health Issues, 23(3), 173-178.

Joyce, T. (2010). Parental consent for abortion and the judicial bypass option in Arkansas: Effects and correlates. Perspectives on Sexual \& Reproductive Health, 42(3), 168-175.

Joyce, T. J., Henshaw, S. K., Dennis, A., Finer, L. B., and Blanchard, K. (2009). The Impact of State Mandatory Counseling and Waiting Period Laws on Abortion: A literature review. New York, NY: Guttmacher Institute.

Joyce, T., Henshaw, S. K., and Skatrud, J. D. (1997). The impact of Mississippi's mandatory delay law on abortion and births. Journal of the American Medical Association, 278(8), 653-658.

Joyce, T., and Kaestner, R. (2000). The impact of Mississippi's mandatory delay law on the timing of abortion. Family Planning Perspectives, 32(1), 4-13.

Kimport, K., Cockrill, K., and Weitz, T. A. (2012). Analyzing the impacts of abortion clinic structures and processes: A qualitative analysis of women's negative experience of abortion clinics. Contraception, 85, $204-210$.

Kumar, A., Hessini, L., and Mitchell, E. M. H. (2009). Conceptualising abortion stigma. Culture, Health and Sexuality, 11(6), 625-639.

Lovan, D. (2018). U.S. abortion clinics face surge of 'emboldened' protesters, survey shows. Available at: https://www.cbsnews.com/news/us-abortion-clinics-face-surge-of-trespassing-and-blockades. (Accessed 15 May 2019).

Madsen, N., Thibodeau, J., and Schubert, E. (2017). Communities need clinics: The role of independent abortion care providers in ensuring meaningful access to abortion are in the United States. Available at: https://www.abortioncarenetwork.org/wp-content/uploads/2017/08/CommunitiesNeedClinics2017.pdf. (Accessed 30 June 2019).

Mahone, R. (2020). Notes on language: Why we stopped using 'surgical abortion' at Rewire. News. Available at: https:/ / rewire.news/article/2020/04/16/notes-language-stopped-using-surgical-abortion/. (Accessed 20 May 2020). 
Martin, L. A., Debbink, M., Hassinger. J., Youatt, E., Eagen-Torkko, M., and Harris, L. (2014). Measuring stigma among abortion providers: Assessing the abortion provider stigma survey instrument. Women and Health, 54(7), 641-661.

Medoff, M. H. (2009). The relationship between state abortion policies and abortion providers. Gender Issues, 26, 224-237.

Mercier, R. J., Buchbinder, M., Bryant, A., and Britton, L. (2015). The experiences and adaptations of abortion providers practicing under a new TRAP Law: A qualitative study. Contraception, 91, 507-512.

Mercier, R. J., Buchbinder, M., and Bryant, A. (2016). TRAP laws and the invisible labor of US abortion providers. Critical Public Health, 26(1), 77-87.

Merriman, S. B., and Tisdale, E. J. (2016). Qualitative Research: A guide to design and implementation (4th ed.). San Francisco, CA: Jossey-Bass.

NARAL Pro-Choice America (2020). About us. Available at: https://www.prochoiceamerica.org/about/. (Accessed 20 May 2020).

Nash, E., Benson-Gold, R., Mohammed, L., Ansari-Thomas, Z. and Cappello, O. (2018). Guttmacher Institute. Available at: Policy trends in the states, 2017. Retrieved from https://www.guttmacher.org/article/2018/01/ policy-trends-states-2017]. (Accessed 18 May 2020).

Nash, E., Mohammed, L., Capello, O., \& Naide, S. (2019). State Policy Trends 2019: A wave of abortion bans, but some states are fighting back. Available at: https://www.guttmacher.org/article/2019/12/state-policy-trends2019-wave-abortion-bans-some-states-are-fighting-back. (Accessed 3 January 2020).

Planned Parenthood Action Fund. (n.d.) Roe v. Wade: The constitutional right to access safe, legal abortion. Available at: https://www.plannedparenthoodaction.org/issues/abortion/roe-v-wad. (Accessed 13 August 2019).

Sandelowski, M. (2000). Whatever happened to qualitative description? Research in Nursing \& Health, 23(4), 334 340.

Sedgh, G., Singh, S., Shah, I., Ahman, E., Henshaw, S. K., and Bankole, A. (2012). Induced abortion: Incidence and trends worldwide from 1995 - 2009. The Lancet, 379(9816), 625-632.

Thomas, D. R. (2006). A general inductive approach for analyzing qualitative evaluation data. American Journal of Evaluation, 27(2), 237-246.

Tong, A., Sainsbury, P., and Craig, J. (2007). Consolidated criteria for reporting qualitative research (COREQ): A 32-item checklist for interviews and focus groups. International Journal for Quality in Health Care, 19(6), 349-357.

Uttley, L., Khaikin, C., and Hasbrouck, P. (2016). Growth of Catholic hospitals and health systems: 2016 update of the Miscarriage of Medicine Report. Available at: http://static1.1.sqspcdn.com/static/f/816571/ 27061007/1465224862580/MW_Update-2016-MiscarrOfMedicine-report.pdf. (Accessed 20 August 2019).

Weinberger, S. E., Lawrence, H., Henley, D. E., Alden, E., and Hoyt, D. B. (2012). Legislative interference with the patient-physician relationship. New England Journal of Medicine 367(16), 1557-1559.

Citation: Crookston, S. (2020). Navigating TRAP Laws, Protesters, and Police Presence at a Midwestern Abortion Clinic in the United States: A Case Study. Feminist Encounters: A Journal of Critical Studies in Culture and Politics, 4(2), 35. https://doi.org/10.20897/femenc/8523

Copyright (C) 2020 by Author/s and Licensed by Lectito BV, Netherlands. This is an open access article distributed under the Creative Commons Attribution License which permits unrestricted use, distribution, and reproduction in any medium, provided the original work is properly cited. 